\title{
CORK SUBERIN AS A NEW SOURCE OF CHEMICALS: 2. CRYSTALLINITY, THERMAL AND RHEOLOGICAL PROPERTIES
}

\author{
N. Cordeiro, ${ }^{a}$ N. M. Belgacem, ${ }^{b}$ A. Gandini ${ }^{b *} \&$ C. Pascoal Neto ${ }^{c}$ \\ "Departamento de Química, Universidade da Madeira, 9000 Funchal, Portugal \\ ${ }^{h}$ Matériaux Polymères, École Française de Papeterie et des Industries Graphiques (INPG), BP 65, 38402 St. Martin d'Heres, \\ France \\ 'Departamento de Química, Universidade de Aveiro, 3810 Aveiro, Portugal
}

(Received 17 March 1997; accepted 5 May 1997)

\begin{abstract}
Suberin samples, obtained by alkaline methanolysis from cork (Quercus suber L.), were submitted to various physical characterizations; DSC, TGA, optical microscopy, density and rheological properties. A substantial proportion of these oligomers possessed a microcrystalline character with a melting range between 0 and $50^{\circ} \mathrm{C}$. The amorphous part was liquid at room temperature and did not display a detectable glass transition upon cooling because of its wide molecular weight distribution. The viscous behaviour of suberin at room temperature was both plastic and thixotropic because of the structuring role of the microcrystals. (C) 1998 Elsevier Science Ltd. All rights reserved.
\end{abstract}

Key words: cork of Quercus suber L., alkaline methanolysis, suberin, thermal characterization, rheological properties, crystallinity, density.

\section{INTRODUCTION}

The outer bark of Quercus suber L., commonly known as cork, is composed of suberin, its main component, contributing to about $40 \%$ of its dry weight, lignin (ca. 20\%), polysaccharides (ca. 20\%) and extractibles (ca. 15\%) (Pereira, 1988). This peculiar chemical composition, characterized by a large contribution from a hydrophobic component (suberin, see below), together with its particular cellular structure (Pereira et al., 1987), give cork excellent barrier properties for polar liquids, heat and sound (Fortes, 1990). Cork finds its main applications in stoppers, boards for insulation and decorative uses and composites (Fortes, 1990). To our knowledge, cork has not been exploited industrially up to now as a source of chemicals.

*Author to whom correspondence should be addressed.
High quality cork for industrial processing is removed only from the trees which are about $40-50$ years old (Fortes, 1990). Thereafter, harvesting takes place periodically in cycles of 9-10 years. The cork industry consumes annually ca. 280000 tons of raw material, of which $20-30 \%$ is rejected, mainly as cork-dust, i.e. a low-granulometry fraction without industrial interest. These tens of thousand of tons of wastes are usually burnt in the mills for energy recovery. It seems however rather uneconomical to destroy in such a manner a product which we believe worthy of a better exploitation. In fact, the unique properties of cork as material could be more rationally used in added-value applications.

For this reason, we recently started a research programme aimed at gaining a deeper insight into the structural features and the chemical properties of cork and its components (Pascoal Neto et al., 1995; Cordeiro et al., 1995; Pascoal Neto et al., 1996; Cordeiro et al., 1997a,b; Gil et al., 1997; Lopes et al., 1997). The end purpose of this broad investigation is to arrive at a sound knowledge of the structureproperties relationships of this natural composite which would make it possible to enhance its usage as material and to valorize it as a source of chemicals.

Within this general context, the study of suberin, which is undoubtedly the most original component of cork compared with those of other more common lignocellulosic materials, took priority in our view. The present series of articles deals therefore with its isolation, thorough characterization and possible utilization both as a specific additive and as macromonomer in polymeric compositions (Cordeiro et al., 1997c).

The structure of suberin is not yet fully established. Kolattukuddy (1977) studied potato periderms and concluded that suberin, in that context, was an aliphatic polyester, similar to cutin, containing phenolic moieties like lignins, as shown in Scheme 1. 
In situ, suberin is a macromolecular network which is therefore insoluble in all solvents. It can, however, be decrosslinked by chemical processes based on the cleavage of the ester moieties. Thus, hydrolysis with aqueous alkali was used by the first cork chemists to isolate suberin from that species, but this approach was later replaced by alkaline alcoholysis (Arno et al., 1981; Holloway, 1972; Holloway and Deas, 1973; Holloway, 1983; Marques and Pereira, 1987). The aliphatic depolymerization products of cork suberin obtained by these procedures were identified by GC and GC-MS techniques and found to consist mainly of 22-hydroxydocosanoic acid, 9,10-dihydroxyoctadecanedioic acid, 18-hydroxyoctadecanoic acid, 9,10,18-trihydroxyoctadecanoic acid, 9-octadecenedioic acid, 9,10-epoxyoctadecanedioic acid, 18-hydroxy-9-octadecenoic acid and 18-hydroxy9,10-epoxyoctadecanoic acid (Holloway, 1972; Arno et al., 1981).

In the previous paper (Cordeiro et al., 1997a) we described a more comprehensive study of these structural features and confirmed that indeed the oligomeric portion of the hydrolysed suberin was found to bear $\mathrm{C}_{16}-\mathrm{C}_{24}$ aliphatic sequences with terminal carboxylic groups and variable amounts of $\mathrm{OH}$ moieties along the chains. However, we also found a distinct feature, not reported previously, consisting of the presence of a fraction possessing a much higher molecular weight. In another recent study (Cordeiro et al., 1997b), we also reported the surface properties of this suberin which are important in the context of its possible applications as an additive in ink, varnishes and other coating compositions.

The present paper is a further contribution to the knowledge of suberin and deals with the characteriz- ation of a number of bulk physical properties, including thermal, morphological and rheological features.

\section{METHODS}

\section{Isolation of suberin}

Suberin was isolated from a powder of high-quality reproduction cork (Quercus suber L.) with a $0.1 \mathrm{M}$ methanolic $\mathrm{NaOH}$ solution following the procedure described previously (Cordeiro et al., 1997a).

\section{Thermal measurements}

Differential scanning calorimetry (DSC) and thermogravimetric analyses (TGA) were carried out with a Setaram DSC 92 analyzer using sealed capsules placed in a stream of dry nitrogen. Samples for DSC weighed ca. $10 \mathrm{mg}$, whereas those for TGA weighed ca. twice this. The molten DSC samples were quenched rapidly in liquid nitrogen and then analyzed by heating-cooling cycles between -150 and $+150^{\circ} \mathrm{C}$, at a rate of $10^{\circ}$ (heating) and $15^{\circ} \mathrm{C}$ per minute (cooling).

\section{Optical microscopy}

The microscopy work was conducted with an OLYMPUS DH2 microscope equipped with a LINKHAM cooling-heating stage which allowed a temperature control of $\pm 0.3^{\circ} \mathrm{C}$. For the crystallization kinetics, a video camera was placed on the ocular system of the microscope in order to record the changes in birefringence intensity as a function of time.

\section{Viscosity}

The viscosity measurements were made with a coneplate CARRIMED-500 rheometer working in the

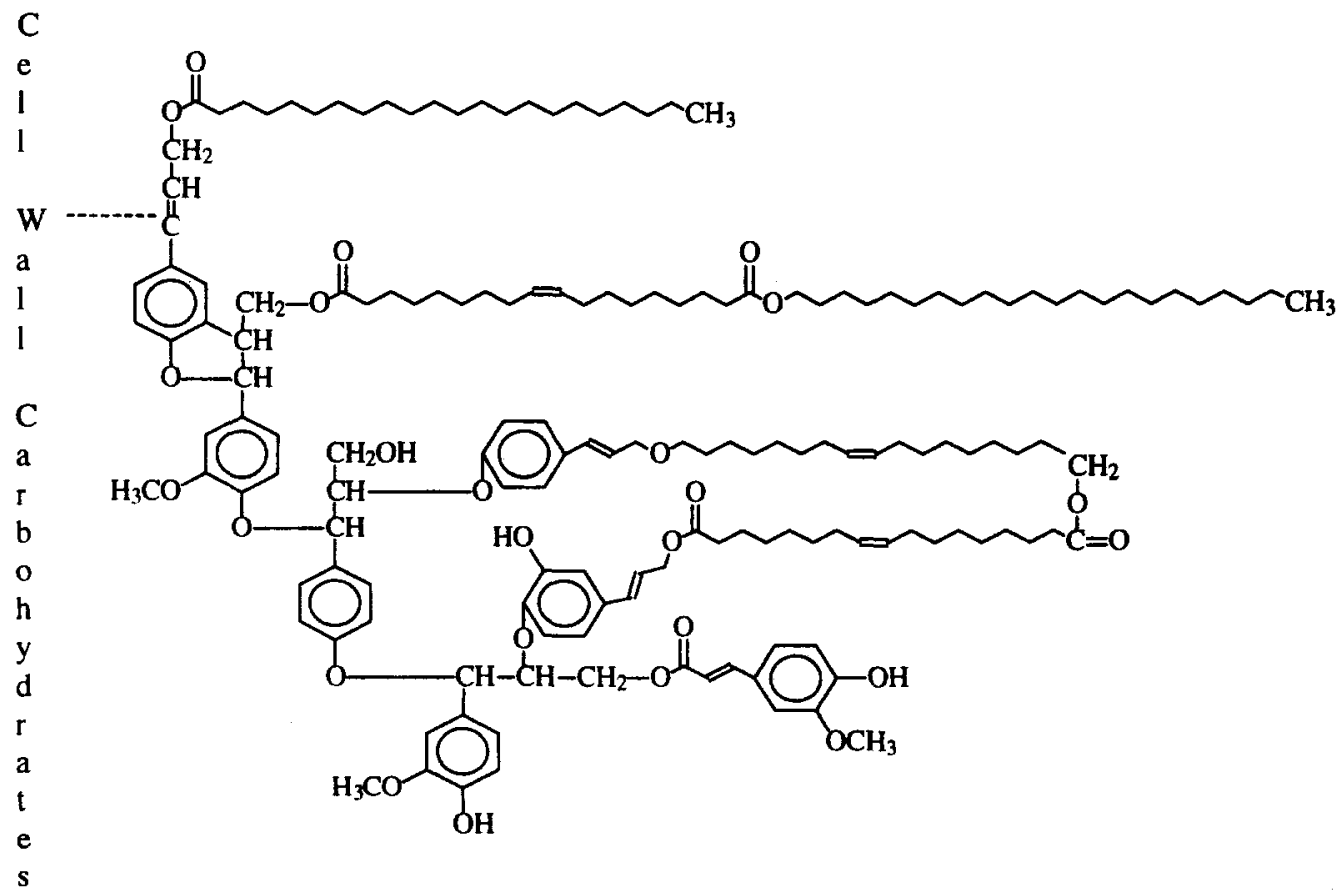

Scheme 1 
controlled-stress mode. The cone used had a $2 \mathrm{~cm}$ diameter and a $4^{\circ}$ angle. Measurements were carried out in the temperatures range of $0-55^{\circ} \mathrm{C} \pm 0.1^{\circ} \mathrm{C}$. The optimized value of the maximum imposed stress (which differed with the working temperature) was selected after testing several options. The time delays associated with the cycles involving stress increase, constant-stress periods and stress decrease were all of $1 \mathrm{~min}$.

\section{Viscoelasticity}

The viscoelastic properties of suberin were measured at ambient temperature with a METRAVIB viscoanalyzer working in a compression mode.

\section{Density}

The density of suberin as a function of temperature was determined with a pycnometer calibrated with water in the $0-70^{\circ} \mathrm{C}$ range. Three independent determinations were carried out at each temperature. The values obtained were reliable to $\pm 0.001 \mathrm{~g} \mathrm{~cm}^{-3}$.

\section{RESULTS AND DISCUSSION}

\section{Thermal and morphological features}

To our knowledge, no DSC study has previously been conducted on suberin. As shown in Fig. 1, the samples, scanned between -20 and $60^{\circ} \mathrm{C}$, displayed a fairly wide endothermic peak with a minimum centred at about $40^{\circ} \mathrm{C}$. The corresponding cooling thermogram, also shown in Fig. 1, exhibited an exo- thermic peak with a maximum at $31^{\circ} \mathrm{C}$. This behaviour can be readily rationalized by a meltingrecrystallization cycle. Quenching the melted suberin in liquid nitrogen did not hinder crystallization as shown by the fact that the thermogram of the frozen sample was entirely similar to that shown in Fig. 1. This experiment was repeated several times and gave the same results, independent of the heating rate. It seems clear that even with very abrupt cooling, the suberin molecules are sufficiently mobile to organize themselves into (micro)crystalline domains.

In order to corroborate this important point, we called upon the observation of suberin by polarizedlight microscopy with heating and cooling procedures. Fig. 2 shows a typical birefringence picture at room temperature of a suberin sample, as obtained with our isolation procedure. The presence

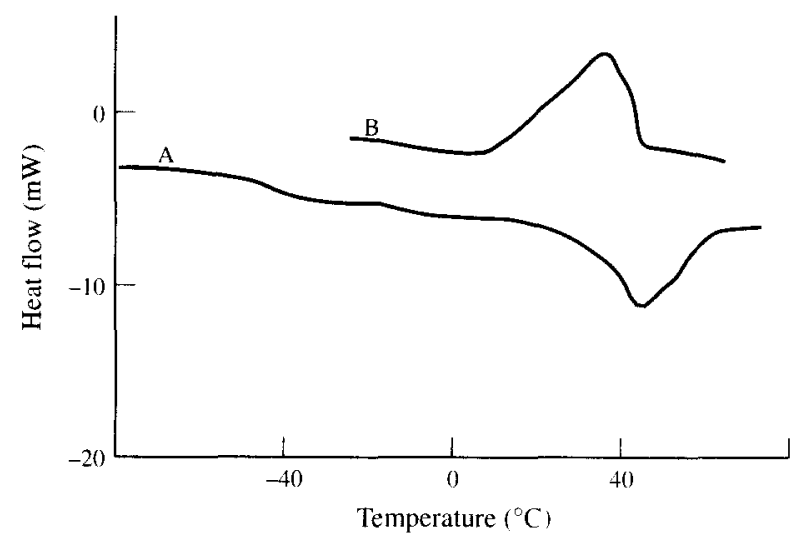

Fig. 1. DSC thermograms of suberin. A. heating; B. cooling.

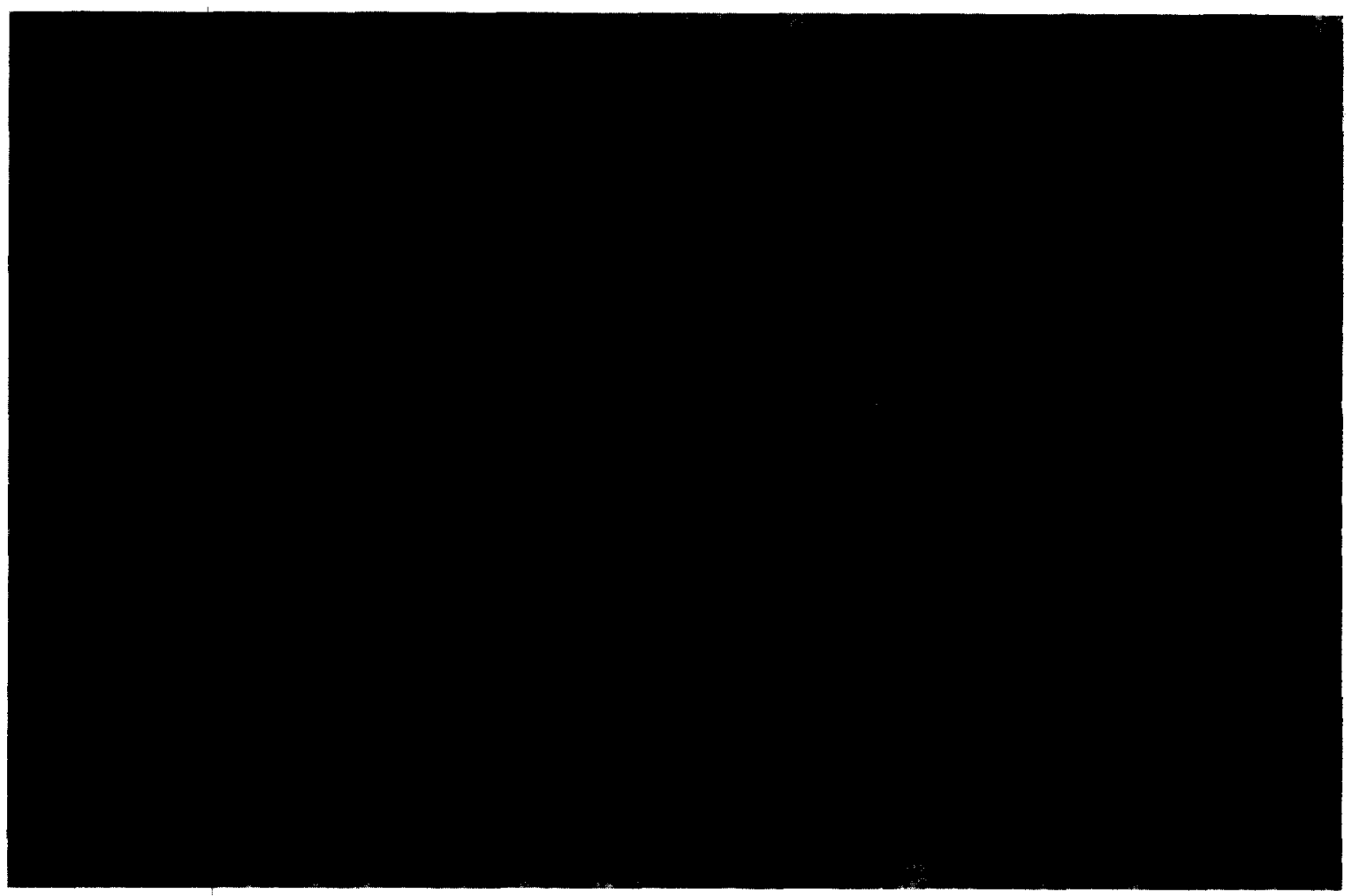

Fig. 2. A typical microscope picture $(\times 30)$ of birefringence from partly crystalline suberin at room temperature. 


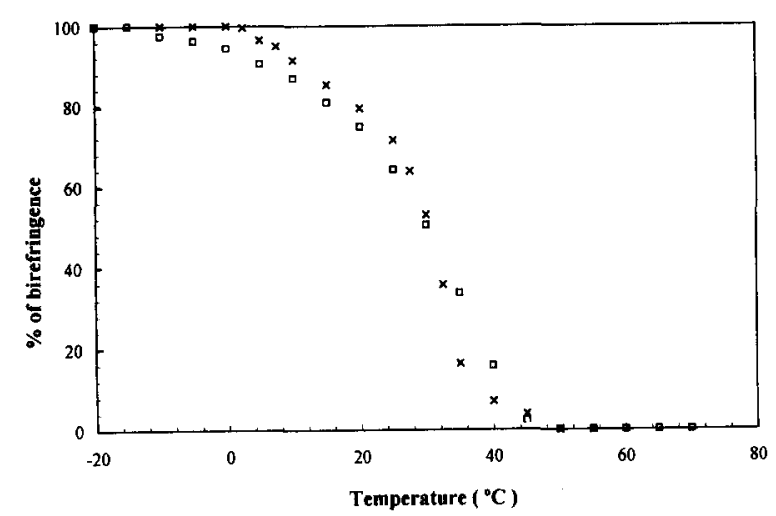

Fig. 3. Melting (X) and recrystallisation ( $\mathrm{D}$ ) of suberin as observed by the change in birefringence intensity as a function of temperature. Note: the $100 \%$ birefringence refers to the maximum extent of crystallization and not to the actual percentage of crystalline phase.

of an important contribution of microcrystalline phases is clearly visible. Heating these samples produced a progressive disappearance of the birefringence and at ca. $50^{\circ} \mathrm{C}$ the field became completely black, confirming the interpretation of the melting behaviour proposed for the DSC endotherms.

A more quantitative study of these melting features was carried out by cooling a pristine sample of suberin to $-20^{\circ} \mathrm{C}$ and following the loss of birefringence as a function of temperature using a heating rate of $5^{\circ} \mathrm{C} \mathrm{min}{ }^{-1}$. After reaching complete melting, the sample was cooled down at the same rate. Fig. 3 shows the results of this experiment which confirm the high mobility of the molecules involved in these phase changes by the remarkable reversibility of the phenomenology. The temperature range covering this melting-recrystallization cycle spanned over some $50^{\circ} \mathrm{C}$, just as the correspondingly wide endothermic peak in the DCS thermograms, although the actual domains were slightly shifted. These observations confirm that our suberin samples are made up of a fairly wide distribution of molecular species, as already encountered in our previous study of their structural features (Cordeiro et al., 1997a). This distribution most probably concerns variations in both molecular weight and detailed chemical composition.

The crystalline character of suberinic structures has never been reported previously, although a mention without comment of the 'melting range' of different suberin fractions was given in a table by Arno et al. (1981). The ease with which the molecules we isolated assemble to give ordered structures recalls the behaviour of paraffins, but here the presence of $\mathrm{OH}$ side groups (Cordeiro et al., 1997a) constitute an element favouring further intermolecular organization through hydrogen bonding.

It is important to emphasize that the $100 \%$ value in Fig. 3 does not refer to total crystallization of the sample, but is simply a reference point. In fact, as clearly visible in all our microscopic observations (see Fig. 2 as a typical example), the doubly polarized field was not entirely filled with luminous domains, suggesting the presence of amorphous (black) zones. This could not be ascribed to liquid crystallizable fractions because cooling to $-150^{\circ} \mathrm{C}$ did not change the relative proportion of bright and dark areas compared with the situation observed at $0^{\circ} \mathrm{C}$ in which, typically, the black areas amounted to as much as $70 \%$ of the field.

Surprisingly however, despite numerous attempts, no clear-cut glass transition corresponding to this solid amorphous phase could be detected by DSC. It seems likely that the absence of typical $\mathrm{Tg}$ signals on the thermograms was not an indication of the absence of the actual glass-liquid transition, but rather a sign of a large temperature interval within which it occurred, in fact too large to give a detectable drop in the baseline. This phenomenon is common among amorphous oligomeric species possessing a wide molecular weight distribution for which the glass transition can span several tens of degrees, as with kraft lignins (Guo et al., 1992).

A typical TGA thermogram of our suberin is given in Fig. 4 and shows the onset of decomposition around $300^{\circ} \mathrm{C}$ with more than $80 \%$ volatilization at $470^{\circ} \mathrm{C}$, the residue being carbonaceous materials.

\section{Rheological properties}

Figure 5 shows a typical rheogram at room temperature which indicates that suberin follows a

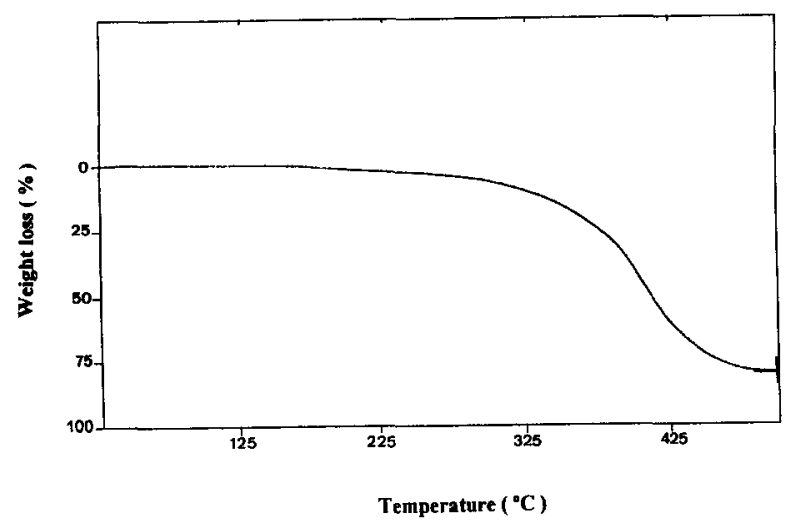

Fig. 4. TGA of suberin in a nitrogen atmosphere.

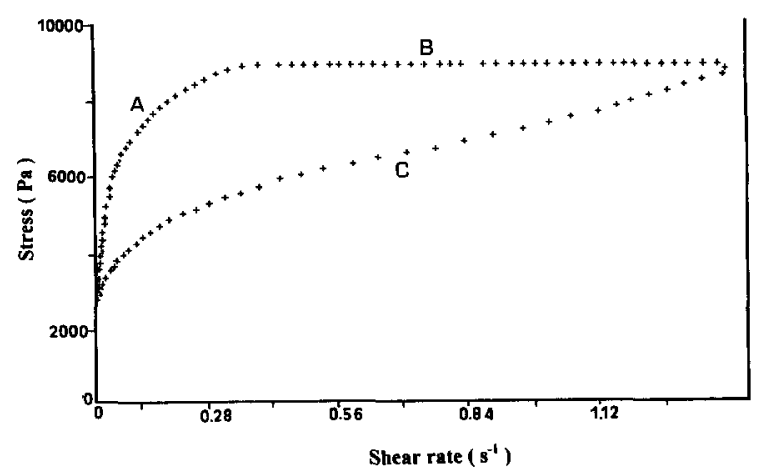

Fig. 5. A typical rheogram of suberin at $20^{\circ} \mathrm{C}$. A: Increasing stress; B: Constant stress; C: Decreasing stress. 


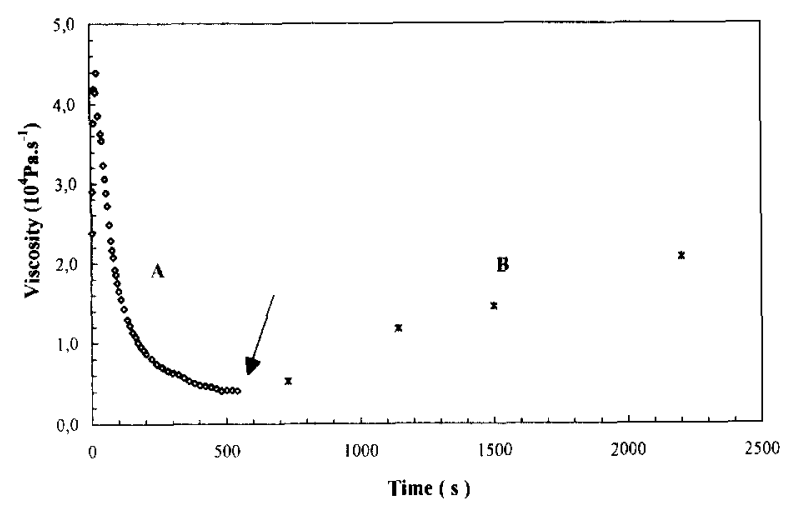

Fig. 6. Variation of suberin viscosity with time: (A) constant stress; (B) at rest. The arrow indicates when the stress was released.

Herschel-Bulkley behaviour (Richardson, 1990). The application of that viscosity model to our rheograms resulted in an excellent agreement characterized by correlation coefficients better than 0.99 . This model is typically employed to fit plastic rheological responses, i.e. the existence of a yield stress, $\sigma_{\mathrm{s}}$ associated with intermolecular cohesive interactions, which can only be destroyed by applying a minimal shear.

Moreover, Fig. 5 also shows a strong contribution of hysteresis in the return curve. The existence of thixotropy in suberin was confirmed by the timedependent experiment shown in Fig. 6 in which the decrease in viscosity as a function of time at constant shear stress was accompanied by a second piece of evidence given by the progressive increase in viscosity after the sample had been left at rest. Usually this type of behaviour is associated with intermolecular or interphase (solid-liquid) shearinduced destructuring followed by time-dependent restructuration at rest. The relevant question here is whether the plastic and thixotropic properties of suberin are to be attributed to the fact that at $20^{\circ} \mathrm{C}$ it is a mixture of liquid and crystalline phases which can establish structuring interactions. Figure 7 shows the rheograms of suberin as a function of temperature which strongly suggest that, indeed, the progressive disappearance of the crystalline particles is accompanied by a tendency towards a Newtonian behaviour. In fact at $50^{\circ} \mathrm{C}$ the samples displayed a

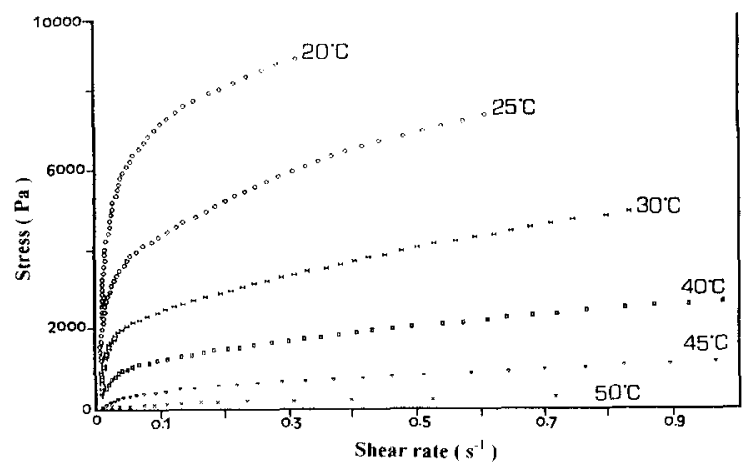

Fig. 7. Rheograms of suberin at different temperatures (increasing stress mode).

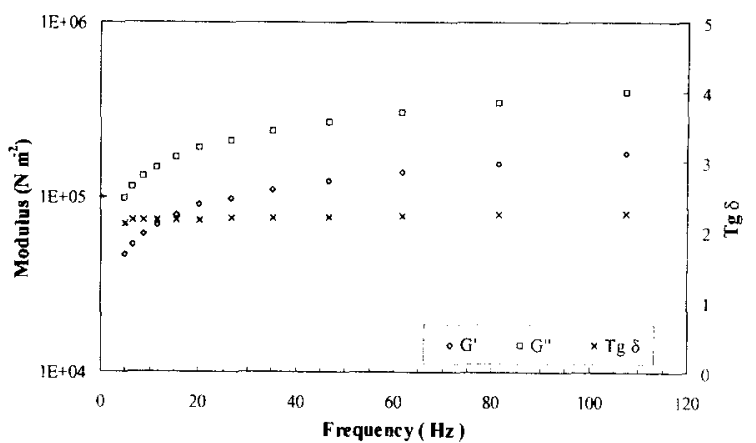

Fig. 8. Dynamic-mechanical behaviour of suberin at room temperature.

linear stress-shear rate correlation with a vanishing small $\sigma_{\mathrm{s}}$. Knowing that at that temperature suberin was practically $100 \%$ liquid (Figs 1 and 3), this rheological behaviour corroborates the interpretation based on crystal-liquid structuring, but the concomitant contribution of intermolecular hydrogen bonding to this feature cannot be ruled out.

The viscoelastic properties of suberin were measured at ambient temperature and are depicted in Fig. 8. The values of the viscous, or loss, $\left(G^{\prime}\right)$ and elastic, or storage, $\left(G^{\prime \prime}\right)$ moduli only showed a modest change with frequency in the range of $5-100 \mathrm{~Hz}$, except at the low values where both decreased. Their ratio $(\tan \delta)$ remained remarkably constant around 2 in favour of the viscous contribution. This overall behaviour is typical of 'viscous liquids'.

\section{Density}

The change in suberin density as a function of temperature is given in Fig. 9. A number of relevant considerations can be drawn from the trends in this plot. First, since below $10^{\circ} \mathrm{C}$ suberin displays its highest (constant) crystallinity and above $60^{\circ} \mathrm{C}$ it is completely liquid (see above), the slope of the plot in Fig. 9, taken between 60 and $70^{\circ} \mathrm{C}$, reflects the thermal expansion coefficient of liquid suberin and that taken between 0 and $10^{\circ} \mathrm{C}$ gives the same coefficient, but for the mixture containing the maximum amount of crystals dispersed into the non-crystallizable liquid. As one would expect, the latter is lower than the former.

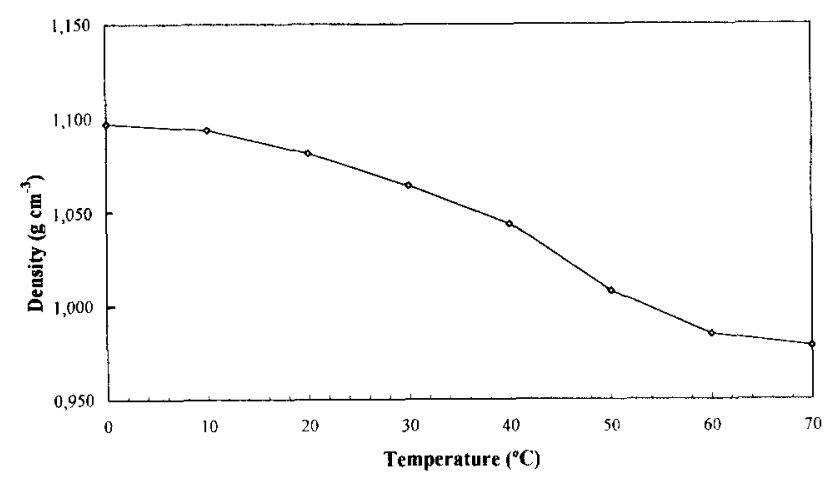

Fig. 9. Temperature dependence of the density of suberin. 
Another interesting point was the more drastic drop in density between 10 and $60^{\circ} \mathrm{C}$ which is an excellent confirmation of the progressive melting of the crystalline phase already detected by DSC and optical microscopy.

As to the actual values, they are remarkably high, even for the liquid. In fact, they only drop below unity around $55^{\circ} \mathrm{C}$, a feature that points to the existence of rather strong intermolecular cohesive interactions. Indeed, alkanes with the same molecular size have much lower densities (ca. $0.7 \mathrm{~g} \mathrm{~cm}^{-3}$ ) because they lack polar moieties and when these are introduced, e.g. two or three lateral $\mathrm{OH}$ goups, the corresponding macropolyols reach densities around $0.9 \mathrm{~g} \mathrm{~cm}^{-3}$. This increase is obviously attributed to the establishment of intermolecular hydrogen bonding, as with the case of ethylene glycol and glycerol which exhibit densities at $20^{\circ} \mathrm{C}$ of 1.11 and $1.26 \mathrm{~g} \mathrm{~cm}^{-3}$, respectively.

The values obtained here for suberin indicate very clearly that this type of interaction plays an important role and confirm the evidence obtained from other results in both this study and the previous one (Cordeiro et al., 1997a).

\section{CONCLUSION}

The most relevant aspect of this investigation was the discovery of the existence of a microcrystalline component in suberin isolated from cork by alkaline methanolysis. A deeper investigation of this interesting feature is in progress particularly in order to establish whether there is any correlation between this crystalline component and one of the two distinct molecular weight fractions found in our structural study (Cordeiro et al., 1997a). Another facet of this work is the strong plastic-thixotropic property of suberin around room temperature, caused by the interactions between the molecules in the liquid phase and the microcrystals suspended in it. Both these features constitute a stimulating incentive to search for applications in the realm of property-enhancing additives, e.g. in the optical quality of coating surfaces or as rheology modifiers.

\section{ACKNOWLEDGEMENTS}

The authors wish to thank the French-Portuguese Scientific Cooperation Programme and JNICT (Portugal) for financial support.

\section{REFERENCES}

Arno, M., Serra, M. C. \& Seoana, E. (1981). Metanolisis de la suberina del corcho - Identificacion y estimacion de sus componentes acidos como esteres metilicos. Anales de Quimica, 77C, 82

Cordeiro, N., Neto, C. P., Gandini, A. \& Belgacem, M. N. (1995). Characterization of the cork surface by inverse gas chromatography. J. Colloid Intetface Sci., 174, 246

Cordeiro, N., Belgacem, M. N., Gandini, A. and Pascoal Neto, C. (1997a) Cork suberin as a new source of chemicals. 1. Extraction and chemical characterization. Int. J. Biol. Macromol., in press.

Cordeiro, N., Aurenty, P., Belgacem, M. N., Gandini, A. and Pascoal Neto, C. (1997b) Surface properties of suberin. J. Colloid Interface Sci., 187, 498.

Cordeiro, N., Belgacem, M. N., Gandini, A. and Pascoal Neto, C. (1997c) Urethanes and polyurethanes from suberin: 1. Kinetic study. Ind. Crops Prods., 6, 163.

Fortes, M. A. (1990) A cortiça. Colóquio Ciência, p. 35.

Gil, A. M., Lopes, M., Rocha, J. and Pascoal Neto, C. (1997) A ${ }^{13} \mathrm{C}$ nuclear magnetic resonance spectroscopy study of cork cell wall structure: the effect of suberin removal. Int. J. Biol. Macromol., 20, 293.

Guo, Z., Pla, F. \& Gandini, A. (1992). Polyesters from lignin. 1. The reaction of kraft lignin with dicarboxylic acid chlorides. Polym. Intern., 27, 17

Holloway, P. J. (1972). The composition of suberin from the corks of Quercus suber L. and Betula pendula R.. Chem. Phys. Lipids, 9, 158

Holloway, P. J. (1983). Some variations in the composition of suberin from the cork layers of higher plants. Phytochem., 22, 495

Holloway, P. J. \& Deas, A. H. B. (1973). Epoxyoctadecanoic acids in plant cutins and suberins. Phytochem., 12, 1721

Kolattukuddy, P. E. (1977) Lipid polymers and associated phenols, their chemistry, biosynthesis, and role in pathogenesis. In The structure, biosynthesis and degradation of wood, eds. F. A. Loewus and V. C. Runeckles, p. 185. Plenum Press, New York.

Lopes, M., Pascoal Neto, C., Evtuguin, D., Silvestre, A., Cordeiro, N. and Gandini, A. (1997) Products of permanganate oxidation of cork, desuberized cork, suberin and lignin. Holzforschung, in press.

Marques, A. V. \& Pereira, H. (1987). On the determination of suberin and other structural components in cork Quercus suber L.. Anais do Instituto Superior de Agronomia-Lisboa, 42, 321

Pascoal Neto, C., Rocha, S., Gil, A., Cordeiro, N., Esculcas, A., Pedrosa de Jesus, J. P., Rocha, S., Delgadillo, I. \& Ferrer Correia, A. J. (1995). Solid-state nuclear magnetic resonance and Fourier-transform infrared studies of thermal decomposition of cork Solid State NMR, 4, 143

Pascoal Neto, C., Cordeiro, N., Seca, A., Domingues, F., Gandini, A. \& Robert, D. (1996). Isolation and characterization of a lignin-like polymer of cork of Quercus suber L.. Holzforschung, 50, 563

Pereira, H., Rosa, M. E. \& Fortes, M. A. (1987). The cellular structure of cork from Quercus suber L.. IAWA Bulletin, 8, 213

Pereira, H. (1988). Chemical composition and variability of cork from Quercus suber L.. Wood Sci. Technol., 22, 211

Richardson, S. M. (1990) Flow of variable-viscosity fluids. In Encyclopedia of Fluid Mechanics, Vol. 9, p. 78. Gulf Publ. Co. Houston, Texas. 